\title{
Participação social como elemento de análise da sustentabilidade: estudo do Programa Brasileiro de DST/AIDS
}

\author{
Social participation as element of sustainability analysis: study on the Brazilian STD/AIDS \\ Program
}

\author{
Maria Matilde Zraik Baracat ${ }^{1}$ \\ Farley Simon Nobre ${ }^{2}$
}

\section{Resumo}

Este artigo apresenta um estudo exploratório sobre a participação social na construção das políticas públicas de controle do HIV/AIDS no Brasil e contribui ao caracterizar a participação social como medida de análise qualitativa da sustentabilidade social. Inicia-se com uma contextualização dos processos de globalização e crescimento populacional que levaram a problemas econômicos, sociais e ambientais evidenciados especialmente a partir da segunda metade do século $X X$ e início do século $X X I$, e que culminaram em maior necessidade de discussão e definição de um desenvolvimento sustentável na sociedade. Apresenta-se um panorama histórico da epidemia da AIDS e, em sua proposta, procura-se inserir a participação social no contexto da sustentabilidade, considerando-se as experiências brasileiras de construção coletiva das políticas públicas que tiveram êxito a partir da Constituição de 1988, com especial atenção à criação da Política Nacional de HIV/AIDS. A pesquisa de campo, de abordagem qualitativa, foi efetuada por meio de entrevistas semiestruturadas, observação não participante e análise documental. Os dados foram examinados por meio da técnica de análise de conteúdo, considerando-se a triangulação entre as diferentes fontes de dados. Conclui-se que a participação social se insere na perspectiva do desenvolvimento sustentável, uma vez que é a partir desse mecanismo que a sociedade civil, especialmente os grupos menos favorecidos, conseguem obter representatividade junto ao Poder Público e contribuir efetivamente com a construção da democracia. Contudo, revelam-se algumas fragilidades específicas relativas ao contexto socioeconômico, cultural e político no Brasil, o que pode comprometer a democratização dos diferentes espaços de escuta da sociedade e a efetivação das políticas públicas relacionadas ao caso em análise.

Palavras-chave: Sustentabilidade social. Participação social. Desenvolvimento sustentável. HIV/AIDS.

\begin{abstract}
This paper presents an exploratory study on social participation in the construction of public policies for HIV/AIDS control in Brazil and it contributes by characterizing social participation as a measure for qualitative analysis of social sustainability. One begins by contextualizing the globalization and population growth processes which led to economic, social, and environmental problems particularly evidenced from the second half of the 20th century and the early $21 \mathrm{st}$

Artigo submetido em 22 de novembro de 2012 e aceito para publicação em 18 de março de 2013.

${ }^{1}$ Mestre em Administração pela Universidade Federal do Paraná; Diretora Administrativa do Hospital Maternidade Victor Ferreira do Amaral/UFPR. Endereço: Hospital de Clínicas/UFPR - Rua Gal. Carneiro 160, Centro, CEP 80060-000, Curitiba - PR, Brasil. E-mail: mariamatilde@ufpr.br; mariamatildezb@gmail.com

PhD em Engenharia de Produção pela Universidade de Birmingham (GB). Professor do Programa de Pós-Graduação em Administração da Universidade Federal do Paraná. Endereço: Av. Pref. Lothario Meissner, 632, º andar, Jardim Botânico, CEP 80210-170, Curitiba - PR, Brasil. E-mail: fsmnobre@gmail.com / Sítio: www.fnobre.com
\end{abstract}


century, culminating in a greater need for discussion and definition of a sustainable development in society. One presents a historical overview of the AIDS epidemic and, according to the proposal, one seeks to include social participation in the sustainability context, taking into account the Brazilian experiences of collective construction of public policies which succeed from the promulgation of the 1988 Constitution, with a special attention to the creation of the HIV/AIDS National Policy. The field research, with a qualitative approach, was conducted through semi-structured interviews, non-participant observation, and documentary analysis. Data were examined through the content analysis technique, taking into account the triangulation between the various data sources. One concludes that social participation is included in the sustainable development perspective, since it's through this mechanism that civil society, especially poorer groups, becomes able to obtain representativeness in the government and effectively contribute to the building of democracy. However, one finds out some specific weaknesses related to the socioeconomic, cultural, and political context in Brazil, something which may compromise the democratization of the various listening spaces of society and the implementation of the public policies related to the case under study.

Keywords: Social sustainability. Social participation. Sustainable development. HIV/AIDS.

\section{Introdução}

Durante o século $\mathrm{XX}$, o mundo presenciou grandes mudanças. A população mundial cresceu em duas gerações mais do que em milhares de anos, ocasionando reflexos diretos nas necessidades de moradia, infraestrutura básica, como transporte, saneamento e acesso à saúde pública, além de uma exploração demasiada e inadequada de recursos naturais, tornando-os cada vez mais escassos (KANDACHAR e HALME, 2008). "Estamos participando em um novo contexto de globalização que se impôs no último meio século, onde a responsabilidade humana pelo globo assume um aspecto ético de garantia da possibilidade de vida futura na terra", afirma Hinkelammert (2006, p. 351), sendo a terra não apenas mais um objeto a ser conquistado, com existência independente da conquista. Essa consciência da crise ambiental moderna, além do aumento da desigualdade social, explosão demográfica, deficiências nas formas de organização social e econômica, consolida-se com uma série de eventos que têm mostrado a necessidade de buscar um modelo alternativo ao crescimento econômico racional e centrado no produto interno bruto (PIB), o qual tem ocasionado danos sobre a natureza (FOLADORI, 2002). Diante de tais desafios, destaca-se um movimento que busca um novo caminho para o desenvolvimento sustentável, cujas premissas receberam maior atenção e difusão a partir da metade do século XX, especialmente por meio: das conferências mundiais da Organização das Nações Unidas em Estocolmo (1972), Rio de Janeiro (1992 e 2012), Quioto (1997) e Joanesburgo (2002); de publicações do Clube de Roma, como "Limites do Crescimento (DONELLA et al., 1972), e da Comissão Mundial sobre Meio Ambiente e Desenvolvimento (CMMAD), conhecido como Relatório Brundtland. Segundo Barbieri et al. (2010, p. 147), "o movimento pelo desenvolvimento sustentável parece ser um dos movimentos sociais mais importantes deste início de século e milênio".

A discussão sobre o desenvolvimento sustentável teve, desde o começo, dois focos: um chamado de sustentabilidade ecológica, referindo-se diretamente à depreciação dos recursos naturais e, um segundo enfoque sobre a sustentabilidade social, onde são consideradas a pobreza e o aumento populacional, sendo que a pobreza é considerada de forma ampliada, incluindo a fome, falta de habitação e infraestrutura, água potável e sistema de saúde (FOLADORI e TOMMASINO, 2000).

Para Omann e Spangenberg (2002), o desenvolvimento sustentável apresenta como objetivo principal proporcionar a todos, em todos os lugares e a qualquer momento, a oportunidade de uma vida digna em sua respectiva sociedade, incluindo a plena participação em um ambiente saudável. O desenvolvimento irá depender, cada vez mais, da maneira como os recursos gerados pelo crescimento econômico serão distribuídos e utilizados, de modo a garantir o bem-estar de todos e de cada um, no presente e no futuro.

O conceito de sustentabilidade e seus critérios possuem um papel central nas reflexões em torno do desenvolvimento, sendo a dimensão social aquela onde se concentram desafios relacionados à pobreza, desigualdade social, equidade e participação social (SACHS, 1997). Contudo, a literatura acadêmica não 
apresenta consenso sobre uma definição de sustentabilidade social, tampouco sobre um conjunto de elementos que podem ser utilizados para analisá-la e caracterizá-la. Em algumas publicações, a sustentabilidade social é referida como meio para alcançar a sustentabilidade ecológica, pois, segundo Rogers, Jalal e Boyd (2008), à medida que aumenta a renda per capita, as pessoas tendem a cuidar melhor do meio ambiente; ao contrário, quando é muito pobre, a pessoa tende a se preocupar primariamente com sua sobrevivência. Em outras publicações, é entendida como uma função ou processo dependente de elementos como saúde social e bem-estar no presente e no futuro (DILLARD e DUJON, 2009). Para alguns autores, a erradicação da pobreza constitui o principal fator da dimensão social da sustentabilidade, estando, portanto, no centro das discussões juntamente com o tema da limitação do crescimento populacional (FOLADORI e TOMMASINO, 2000; ROGERS, JALAL e BOYD, 2008). No entanto, considerando uma série de questões de conjuntura socioeconômica e política, tais como o processo de democratização (PNUD, 1993), e o objetivo de melhorar a qualidade de vida da população como um todo (SACHS, 1993), outros elementos têm sido incorporados à análise da sustentabilidade social. Entre esses elementos inclui-se uma participação social que vai além da obrigatoriedade do voto e ressalta a condição do indivíduo ser autônomo e capaz de decidir sobre aspectos da sua vida pessoal e coletiva (STIGLITZ, 2002). Embora alguns trabalhos mencionem a sustentabilidade como dependente da participação social, poucos são os estudos que a utilizam como indicador de sustentabilidade social (OMANN e SPANGENBERG, 2002; LITTIG e GRIEBLER, 2005).

A Comissão Econômica para a América Latina e o Caribe (Cepal) (2011) afirma que a criação de mecanismos internacionais de defesa da cidadania, da democracia, da igualdade entre os sexos e do respeito à diversidade étnica vinculam-se ao rompimento de estruturas arcaicas de dominação e controle do poder. Desde a década de 1990 a América Latina, em seu conjunto, vem reduzindo a desigualdade, a pobreza e a indigência (LUSTIG e LÓPEZ-CALVA, 2012) e tem apresentado um bom crescimento econômico, apesar das grandes diferenças entre os países (CEPAL, 2011). No entanto, as iniquidades em saúde, ou seja, aquelas desigualdades em saúde que, além de sistemáticas e relevantes, também são evitáveis, injustas e desnecessárias, ainda são um dos traços marcantes da situação da saúde no Brasil, devido, em parte, às grandes desigualdades entre os diversos estratos sociais e econômicos da população (FIOCRUZ, 2008). A epidemia da AIDS surgiu em um momento no qual os países industrializados acreditavam que as doenças infecciosas estavam controladas pela tecnologia e pela evolução da medicina moderna (GRECO, 2008). Devido à sua gravidade e letalidade, associadas à dificuldade de efetivar meios preventivos, à falta de medicamentos eficazes, à grande quantidade de doenças oportunistas e à disseminação global, surpreendeu a todos e inseriu novas discussões no estabelecimento de programas de saúde pública, colocando a participação da sociedade na formulação, implementação e acompanhamento de políticas públicas de controle e prevenção da AIDS (MONTEIRO, 2006). Após três décadas de manifestação da AIDS, observa-se que o controle dessa patologia, que passou de infecção fatal a doença crônica, continua a representar um desafio para o desenvolvimento econômico e social nos diferentes continentes, além de atestar a relevância da discussão integrada dos direitos humanos em políticas sociais (CARVALHO, 2008). O Brasil foi o primeiro país em desenvolvimento a adotar uma política pública de acesso a tratamento antirretroviral e, desde a década de 1980, o país tem implementado campanhas educativas e de prevenção (BRASIL, 2010), o que tem gerado benefícios inequívocos, tanto no âmbito coletivo como individual, além de servir de exemplo do modo como deve ser a atuação do sistema de saúde brasileiro em relação a campanhas de conscientização, parceria com a sociedade civil e monitoramento cuidadoso (GRANGEIRO et al., 2006).

Este artigo apresenta um recorte de uma pesquisa mais ampla, na qual foram analisadas as contribuições do Programa Brasileiro de DST/AIDS para a sustentabilidade social. Ele contém os resultados obtidos por meio da análise da participação da sociedade nas definições das políticas públicas do Programa Brasileiro de HIV/AIDS. Procura-se considerar os avanços propostos na literatura e contribuir com o campo de estudo por meio da caracterização da participação como possível elemento de análise qualitativa da sustentabilidade social. Inicia-se com uma contextualização dos processos de globalização e crescimento populacional que levaram aos problemas econômicos, sociais e ambientais vivenciados especialmente a partir da metade do século XX e início do século XXI e que culminaram nas discussões e na disseminação de conceitos de desenvolvimento sustentável e sustentabilidade. São apresentados os aspectos históricos e sociais da epidemia de AIDS, bem como o processo de construção da resposta brasileira ao desafio do controle da 
AIDS. Foi realizada uma pesquisa qualitativa, de nível exploratório, mais especificamente um estudo de caso tendo como unidade de análise o Programa Brasileiro de DST/AIDS. A coleta dos dados foi realizada por meio de observação não participante, pesquisa documental e entrevistas semiestruturadas com dezenove atores que protagonizam esse processo. Os dados foram analisados por meio da técnica de analise de conteúdo, considerando-se a triangulação entre as diferentes fontes de dados.

\section{Contexto Global}

Previamente à Revolução Industrial (século XVIII), os padrões de crescimento demográfico mantiveram-se bastante estáveis, com a população humana aumentando lentamente (BLOOM e CANNING, 2006). No ano de 1800, a população mundial era de aproximadamente 1 bilhão de habitantes, tendo alcançado o número de 7 bilhões em 2012. Rogers, Jalal e Boyd (2008) chamam a atenção para a aceleração desse crescimento demográfico, pois enquanto se demorou 130 anos para que a população da Terra atingisse a marca de 2 bilhões de pessoas (1930), em 1960, apenas 30 anos mais tarde, foi atingida a marca de 3 bilhões e 15 anos mais tarde (1975) a população chegou a 4 bilhões. Essa grande aceleração na taxa de crescimento demográfico é um dos motivos do aumento das preocupações a respeito do uso dos recursos naturais não renováveis. Essas mudanças demográficas, além de progressos no transporte, informação e comunicações, tiveram impacto direto sobre a economia global e os meios de organização e produção, resultando em uma sociedade que, segundo Ianni (1999, p. 39), apresenta "um desenvolvimento desigual e contraditório, mas é articulada globalmente". A Cepal $(2002$, p. 17) refere-se à "crescente gravitação dos processos financeiros, econômicos, ambientais, políticos, sociais e culturais de alcance mundial sobre aqueles de caráter regional, nacional ou local como globalização contemporânea". Sen (2002) lembra que, a partir de uma perspectiva histórica, a globalização tem contribuído há milênios para o progresso do mundo por meio das viagens, do comércio e das migrações, com a difusão da cultura e do conhecimento entre os povos. Segundo Hart (2006), a queda dos regimes comunistas transformou o capitalismo no sistema econômico predominante, impondo uma civilização e uma economia praticamente planetárias. Hobsbawm (2010) avalia que o fracasso da União das Repúblicas Socialistas Soviéticas (URSS) chamou a atenção basicamente para o fracasso do comunismo soviético, ou seja, da tentativa de basear toda uma economia na propriedade universal, pelo Estado, dos meios de produção e no planejamento central que tudo abrangia, sem qualquer recurso efetivo ao mercado ou aos mecanismos de preço. Por outro lado, avalia, ainda, que as economias nas quais os recursos eram alocados inteiramente pelo mercado, sem qualquer restrição, em condições de competição ilimitada, geravam cada vez mais riqueza, mas não para todos, pois a diferença entre ricos e pobres, mesmo nos países desenvolvidos, havia aumentado. Callinicos (2006, p. 254) afirma que "a pobreza em massa persiste em um contexto de crescimento mundial da desigualdade". É bem conhecida a "associação entre pobreza e outros elementos promotores de sofrimento e opressão, tais como doenças, maiores índices de analfabetismo, violência, saneamento básico precário, maior dificuldade de acesso a serviços de saúde em todos os níveis de atenção" (COTTA, CAZAL e RODRIGUES, 2009, p. 278).

A pobreza é mais que baixa renda, lembram Kandachar e Halme (2008), e deve haver uma distinção do que é a pobreza real material e a percepção cultural da pobreza. Esses autores salientam que as pessoas não morrem pela falta de renda, mas, sim, pela falta de recursos, e citam como exemplos comunidades que vivem em locais distantes, como as montanhas do Himalaia, onde a biodiversidade ainda não foi destruída e cuja renda é menor que US\$ 1 ao dia, mas que vivem bem dentro de suas possibilidades, com acesso aos recursos de que necessitam, e elas não se consideram pobres; por outro lado, há pessoas com renda maior que US\$ 5 ao dia, mas que não conseguem ter acesso aos recursos necessários, sendo estas, sim, consideradas pobres. Prahalad (2010) esclarece que os 4 bilhões de pessoas que compõem a base da pirâmide econômica, vivendo com uma renda inferior a US\$ 1.500 anuais representam uma extrema variedade social, que se reflete em seus níveis de alfabetização, na composição rural/urbano, na mistura geográfica, nos níveis de renda, nas diferenças culturais e religiosas e em qualquer base de segmentação que se possa conceber. Hart (2006, p. 2) afirma que "a base da pirâmide não representa nem um país e nem um mercado e sim uma categoria demográfica, pois cada país tem uma base da pirâmide incluindo Estados Unidos, Japão e Europa Ocidental”. Para Sen (2002), o problema são as desigualdades internacionais e intranacionais da riqueza, a 
distribuição dos benefícios potenciais da globalização entre os países ricos e pobres e entre os diversos grupos de um mesmo país.

Para Boyle e Boguslaw (2007), a pobreza ocorre não apenas devido à insuficiência de rendimentos financeiros, mas, também, devido à falta de serviços sociais e públicos e investimentos em educação, cuidados primários de saúde, água e saneamento, transporte e energia. Segundo esses autores, ainda, a pobreza é agravada por uma distribuição desigual de poder e por limites sobre a participação política; assim, as políticas para promoção do desenvolvimento econômico e humano precisam concentrar-se não só no rendimento, mas em fatores como serviços sociais, desenvolvimento de infraestrutura, segurança humana e participação política democrática. Isso inclui melhoramentos no acesso à saúde, educação, nutrição, saneamento básico e transporte e aumentar as oportunidades oferecidas a grupos marginalizados na sociedade.

\section{Desenvolvimento Sustentável}

O desenvolvimento sustentável é um conceito dinâmico, em constante evolução, que tem assumido diversas definições na literatura, sendo contingencial a contextos culturais, interdisciplinares, temporais e locais (GLADWIN, KENNELLY e KRAUSE, 1995; ROGERS, JALAL e BOYD, 2008). Sua formação como conceito, mais especificamente na economia, evoluiu por meio de reflexões de pesquisadores a partir da Revolução Industrial, no Século XVIII, que, sob muitos aspectos, representou uma ruptura nas relações entre homem e natureza, onde foram estabelecidos os caminhos de uma economia predatória que consome em um ritmo vertiginoso os recursos naturais sem assegurar sua reprodução (HAWKEN, LOVINS e LOVINS, 1999; NOBRE, WALKER e HARRIS, 2011; VIVIEN, 2011). Contudo, o conceito de desenvolvimento sustentável se tornou mais difundido a partir da metade do século XX, por meio de publicações do Clube de Roma e da Organização das Nações Unidas (ONU), especialmente da Comissão Mundial Sobre Meio Ambiente e Desenvolvimento, criada pela Assembleia Geral da ONU em 1983. Em "Nosso Futuro Comum", definiu-se que o desenvolvimento sustentável deve garantir o atendimento às necessidades do presente sem comprometer a capacidade das futuras gerações atenderem às suas necessidades (WCED, 1987). Assim, a sustentabilidade pode ser compreendida como um conjunto de critérios que, quando satisfeitos, podem atender às necessidades do presente sem comprometer a possibilidade das futuras gerações atenderem às suas necessidades; e o desenvolvimento sustentável se caracteriza como caminhos ou conjuntos de estratégias planejadas e deliberadas para contribuir com a sustentabilidade, uma vez que o desenvolvimento supõe uma transformação progressiva da economia e da sociedade (NOBRE, WALKER e HARRIS, 2011; WCED, 1987). Gladwin, Kennelly e Krause (1995) definem que o desenvolvimento sustentável envolve um processo para alcançar o desenvolvimento humano, de maneira inclusiva, interligada, igualitária, prudente e segura. Segundo a Unesco (2005), o objetivo final é "alcançar a coexistência pacífica entre os povos, reduzir o sofrimento, a fome e a pobreza, em um mundo onde as pessoas possam exercer dignamente seus direitos como seres humanos e cidadãos", onde se ressalta a necessidade de uma constante abordagem holística para compreender as complexidades nas inter-relações entre o meio ambiente e o homem (UNESCO, 2005).

Até o início dos anos 1960, segundo Veiga (2008, p. 18), "não havia a necessidade de distinguir desenvolvimento de crescimento econômico, pois as poucas nações desenvolvidas eram as que haviam se tornado ricas pela industrialização". Porém, o aumento crescente da riqueza não oferecia liberdades elementares às pessoas, como a garantia de nutrição adequada, medicamentos para doenças tratáveis, vestimenta ou moradia apropriada (SEN, 2009). Nesse raciocínio, Sachs (1986) considera o crescimento condição necessária, mas de modo algum suficiente para o desenvolvimento, pois pode subentender, em alguns momentos, desenvolvimento e, em outros, o mau desenvolvimento. Stiglitz (2002) afirma que o desenvolvimento representa uma transformação da forma tradicional de pensamento, das relações tradicionais da sociedade, da forma tradicional de lidar com educação e saúde e dos métodos tradicionais de produção. Uma das características das sociedades tradicionais é a aceitação do mundo como ele é, e a perspectiva moderna reconhece a capacidade de indivíduos e sociedades realizarem mudanças. Segundo Sachs (1993, p. 19): 
[...] são necessárias estratégias de desenvolvimento onde o crescimento não seja um objetivo, per se, como tem se pensado há décadas, externalizando livremente seus custos sociais e ambientais e ampliando a desigualdade econômica e social entre as nações e dentro delas. $\mathrm{O}$ crescimento pela desigualdade, baseado em uma economia de mercado sem controles, pode somente aprofundar a cisão entre Norte e Sul e a dualidade interna da sociedade e, a rigor, sua tendência é exacerbar o círculo vicioso da pobreza e da degradação ambiental.

Para a Comissão Mundial sobre Meio Ambiente e Desenvolvimento (CMMAD), em seu relatório "Nosso Futuro Comum", não é possível separar o desenvolvimento humano do desenvolvimento sustentável. O desenvolvimento humano é um processo de alargamento das escolhas das pessoas. As mais vitais são levar uma vida longa e saudável, receber instrução e desfrutar um padrão de vida digno (PNUD, 2011). Segundo Nidumolu, Prahalad e Rangaswami (2009), não há alternativa ao desenvolvimento sustentável. O movimento contra a degradação ambiental é muito grande na atualidade. Centenas de organizações não governamentais (ONGs) e praticamente todos os governos e órgãos oficiais do mundo lutam pelo controle da poluição e pela preservação da natureza como forma de garantir a qualidade de vida em nosso planeta (OLIVEIRA, 2002). Em essência, o desenvolvimento sustentável é um processo de transformação no qual a exploração dos recursos, a direção dos investimentos, a orientação do desenvolvimento tecnológico e a mudança institucional se harmonizam e reforçam o potencial presente e futuro, a fim de atender às necessidades e aspirações humanas (CMMAD, 1991). Segundo Bezerra e Bursztyn (2000) apud Barbosa (2008, p. 53): “O desenvolvimento sustentável é um processo de aprendizagem social de longo prazo que, por sua vez, é direcionado por políticas públicas orientadas por um plano de desenvolvimento nacional".

Almeida (2007) analisa, ainda, que a publicação anual dos Relatórios de Desenvolvimento Humano (RDH) desde 1990 tem suscitado a discussão e análise de objetivos globais capazes de sustentar resultados positivos ao longo do tempo, especialmente no sentido de combater a pobreza e a desigualdade. Assim, foi aprovada, em setembro de 2000, uma lista de objetivos de desenvolvimento econômico, social e ambiental, os denominados Objetivos do Milênio (ODMs). São metas ambiciosas destinadas a corrigir as deformações do planeta causadas pela desigualdade social e pela utilização predatória dos recursos naturais e, segundo o Programa das Nações Unidas para o Desenvolvimento (PNUD), elas são baseadas em um conjunto de valores fundamentais, como a liberdade, a igualdade, a solidariedade, a tolerância, o respeito pela natureza e a responsabilidade partilhada.

Sachs (1993, p. 25-26), “discutindo a questão do desenvolvimento sustentável, aponta cinco dimensões de sustentabilidade dos sistemas econômicos que devem ser observadas para planejar o desenvolvimento: social, econômica, ecológica, espacial e cultural". Assim:

- O objetivo da sustentabilidade social é melhorar os níveis de distribuição de renda, com a finalidade de diminuir a exclusão social e a distância (econômica) que separa as classes sociais.

- O objetivo da sustentabilidade econômica diz respeito a aumentos da eficiência do sistema, seja na alocação de recursos ou em sua gestão.

- O objetivo da sustentabilidade ecológica envolve a preservação do meio ambiente sem, contudo, comprometer a oferta dos recursos naturais necessários à sobrevivência do ser humano.

- O objetivo da sustentabilidade espacial refere-se ao tratamento equilibrado da ocupação rural e urbana, assim como a uma melhor distribuição territorial das atividades econômicas e dos assentamentos humanos.

- O objetivo da sustentabilidade cultural diz respeito à alteração dos modos de pensar e agir da sociedade, de modo a despertar uma consciência ambiental que provoque redução do consumo de produtos causadores de impactos ambientais negativos. 
Considerando essas dimensões, na visão de Sachs (1993), consegue-se atingir o desenvolvimento sustentável. A busca de uma nova linguagem, capaz de expressar uma expansão da agenda ambiental para a sustentabilidade e a necessidade de tratar os negócios a partir das perspectivas social, ambiental e econômica, resultou na criação do termo triple bottom line (ELKINGTON, 1994; 1997), cujo propósito é prestar atendimento de forma equilibrada às pessoas, ao planeta e ao lucro (IPIRANGA, GODOY e BRUNSTEIN, 2011). Nessa perspectiva de análise, Vellani e Ribeiro (2009, p. 190) complementam que: "As sociedades nascem e se desenvolvem por meio de organizações, instituições e empresas que operam para atender às necessidades das pessoas. Erigir um desenvolvimento sustentável pode significar organizações, instituições e empresas atuando em suas regiões para satisfazerem as necessidades da população presente sem comprometer a capacidade das futuras gerações em satisfazerem suas próprias necessidades". Para Barbieri et al. (2010), a sustentabilidade de um negócio pode ser entendida como a capacidade de gerar recursos para remunerar os fatores de produção, repor os ativos usados e investir para continuar competindo. Os autores afirmam que se a sustentabilidade dos negócios for entendida como uma contribuição efetiva para o desenvolvimento sustentável, os resultados obtidos devem ser econômicos, sociais e ambientais. Segundo Hart e Milstein (2004), "a ideia de sustentabilidade vem sendo representada pela elevação das expectativas em relação ao desempenho social e ambiental" e, nesse contexto, esses autores propõem a criação de valor sustentável para a empresa, a partir da ideia de que os desafios globais associados à sustentabilidade, quando considerados sob a ótica dos negócios, podem ajudar a identificar estratégias e práticas que, ao mesmo tempo que sejam capazes de contribuir com um mundo mais sustentável, também aumentem o valor para o acionista. Para os autores, as empresas podem criar valor ao atender às necessidades daqueles localizados no extremo inferior da pirâmide de renda do mundo, e isso de uma forma que facilite a criação e distribuição de renda inclusiva. No entanto, Hart e Milstein (2004) também avaliam que algumas poucas empresas têm começado a tratar a sustentabilidade como uma oportunidade de negócio, abrindo caminho para a diminuição de custos e riscos, ou mesmo elevando seus rendimentos e sua participação de mercado por meio da inovação. A criação de valor sustentável para o acionista irá depender da habilidade da empresa de criar e renovar as suas capacidades em favor do amanhã, sendo que a sustentabilidade é um conceito amplo e multidimensional, não podendo ser equacionado apenas por meio de uma única ação corporativa.

Muitas empresas ainda têm noção de que, ao aderir à sustentabilidade, irão obter como resultado a redução da competitividade, além de ficar em desvantagem diante daquelas que não adotarem os mesmos princípios (NIDUMOLU, PRAHALAD e RANGASWAMI, 2009). Esses autores estudaram as iniciativas de sustentabilidade de 30 grandes corporações durante algum tempo e sua pesquisa demonstra que a sustentabilidade é um "filão" de inovações organizacionais e tecnológicas, capaz de reduzir custos na utilização de insumos e gerar receitas adicionais a partir da produção de produtos melhores ou pela criação de novos negócios. A conclusão deles é que as abordagens tradicionais de negócios entraram em contradição com as necessidades de sustentabilidade e as empresas devem desenvolver soluções inovadoras, o que irá ocorrer somente quando houver o reconhecimento de que a sustentabilidade pode ser resultante e propulsora de inovações (NIDUMOLU, PRAHALAD e RANGASWAMI, 2009). Em uma linha semelhante de raciocínio, Porter e Kramer (2011) propõem a criação do valor compartilhado, que envolve a criação de valor econômico, por meio de práticas e políticas operacionais capazes de aprimorar a competitividade da empresa e, ao mesmo tempo, criam valor social compartilhado, no sentido de melhorias concretas para a sociedade em seu âmbito de atuação. Para os autores, os mesmos princípios de valor compartilhado podem ser aplicados a governos e organizações sem fins lucrativos, pois estes serão mais eficazes se pensarem em termos de valor, considerando os benefícios em relação ao custo e o foco nos resultados alcançados. A partir da perspectiva da sociedade, não importa qual tipo de organização irá criar o valor; o que importa são os benefícios entregues por aquelas organizações ou combinações de organizações a partir do uso adequado de seus recursos. Considerando as proposições desses autores, a sustentabilidade deve ser um valor presente nas organizações independentemente de seu porte, sua área de atuação ou vinculação junto à sociedade.

A organização sustentável, considerando o triple bottom line, ou os três pilares da sustentabilidade (econômico, social e ambiental), irá contribuir com o desenvolvimento sustentável de sua comunidade ou país. Uma das questões mais preocupantes para esse fim é o aumento da desigualdade social (RODRIGUES, 1993 apud OLIVEIRA, 2002), e, nesse sentido, para Rogers, Jalal e Boyd (2008), a pobreza é a mais significativa dimensão socioeconômica do desenvolvimento sustentável, sendo seu aspecto mais óbvio o 
físico, como fome, doenças, longas horas de trabalho, ambientes de trabalho insalubres, habitações precárias, necessidades básicas não atendidas e há, ainda, aspectos legais, emocionais e morais. Essa análise demonstra claramente a inter-relação entre o triple bottom line, ao mesmo tempo que coloca a importância da dimensão social da sustentabilidade para alcançar o desenvolvimento sustentável.

\section{Dimensão Social da Sustentabilidade}

O conceito de sustentabilidade social tem gerado muitas polêmicas teóricas ao longo dos últimos trinta anos e, até o presente, não há um consenso sobre ele (LITTIG e GRIEBLER, 2005; DILLARD e DUJON, 2009). Até a década de 1990, duas temáticas concentravam essa discussão: a pobreza e o crescimento populacional. Segundo Foladori (2002, p. 106):

Reduzir a pobreza e limitar o crescimento populacional constituíam os objetivos de todo programa de sustentabilidade social. Obviamente, questões como equidade, qualidade de vida, entre outras, estavam presentes, porém, aqueles eram os temas centrais em nível mundial.

Para Harris e Goodwin (2001) citados em Dillard e Dujon (2009, p. 53): "Um sistema socialmente sustentável alcança a equidade na distribuição e oportunidades, o fornecimento adequado de serviços sociais incluindo saúde e educação, igualdade de gênero e a responsabilidade política e participação". Nessa definição são incorporados alguns elementos, como a igualdade de gênero, participação social e responsabilidade política, os quais vão além da questão da redução da pobreza e melhor distribuição de renda. No entanto, Rogers, Jalal e Boyd (2008, p. 219) afirmam que: "É universalmente reconhecido que a erradicação da pobreza é o fator mais importante que rege a dimensão social do desenvolvimento sustentável".

Para Sachs (1993, p. 25):

A sustentabilidade social significa a promoção de uma sociedade com maior equidade na distribuição de renda, garantindo direitos e condições de uma vida digna à população, diminuindo a distância entre ricos e pobres, significando a consolidação de um processo de desenvolvimento que tem como objetivo a melhoria da qualidade de vida da população como um todo.

Nesse sentido, o desenvolvimento deve ser considerado em sua multidimensionalidade, abrangendo todo o espectro de necessidades materiais e não materiais, como enfatiza o PNUD no relatório sobre o desenvolvimento humano. Dillard e Dujon (2009) acrescentam que é necessária a existência de programas sociais capazes de gerar saúde social e bem-estar agora e no futuro. Littig e Griebler (2005) caracterizam a sustentabilidade social como uma qualidade das sociedades, considerando a satisfação das necessidades humanas, preservação da natureza e das capacidades reprodutivas, além do atendimento de reivindicações como justiça social, dignidade humana e participação. Para Rogers, Jalal e Boyd (2008), há dez dimensões de caráter social que devem ser discutidas dentro da perspectiva de desenvolvimento sustentável: a redução da pobreza, a participação social na discussão das políticas sociais, a construção de consenso entre os stakeholders envolvidos nos processos de discussão das políticas sociais, a função das Organizações Não Governamentais, a promoção da igualdade de gênero, planejamento habitacional, melhoria das condições de vida dos povos indígenas, políticas de inclusão social, projetos de impacto social positivo considerando infraestrutura básica como transporte, saneamento e abastecimento de água e, por último, a construção de indicadores de desenvolvimento social.

Omann e Spangenberg (2002) sugerem que um dos indicadores utilizados para medir a sustentabilidade social seja a medida da capacidade e da satisfação com a participação política, não apenas com o voto, a partir da clareza desses autores de que a participação dos cidadãos nas decisões capazes de afetar suas vidas 
pode ser considerada um dos elementos centrais da medida da sustentabilidade social. O Relatório de Desenvolvimento Humano (RDH) de 1993 elaborou essa análise e concluiu que a participação social tornouse uma questão central, considerando a transição democrática de muitos países, e salientou que a participação é um processo e não um evento, processo este com velocidades diferentes entre os países e as regiões, entre sua forma e extensão e que é importante medir não apenas o nível de participação, mas, também, se a participação está aumentando. Nesse sentido, entende-se participação como a capacidade das pessoas de intervir estreitamente em seus processos econômicos, sociais, culturais e políticos que afetam suas vidas. E, assim, enfatizou que a participação é um elemento essencial do desenvolvimento humano. Esses argumentos são reiterados no RDH de 2004, que salientou que o desenvolvimento depende da maneira como os recursos gerados pelo crescimento econômico são utilizados; e os resultados humanos, como participação democrática na tomada de decisão ou igualdade de direitos para homens e mulheres, não dependem dos rendimentos (VEIGA, 2008).

\section{Participação Social e Sustentabilidade}

A participação social é considerada um elemento indissociável das discussões sobre o desenvolvimento sustentável, na medida em que promove o compartilhamento de conhecimentos e a negociação das relações de poder, facilitando a implementação de ações socioambientais de forma mais custo-efetiva, apesar da complexidade que apresenta (TOTH, MERTENS e MAKIUCHI, 2012), e tem sido colocada desde a década de 1980 por agências internacionais e ONGs como um objetivo necessário dos programas de desenvolvimento e sustentabilidade (FOLADORI, 2002). O direito do cidadão de participar ativamente em todas as instâncias da sociedade em que está inserido é um dos elementos da sustentabilidade social segundo Omann e Spangenberg (2002). Pretty (1995) já enfatizava que havia um número crescente de estudos comparativos de projetos de desenvolvimento mostrando que a participação era um dos elementos essenciais do sucesso. Na visão de Rogers, Jalal e Boyd (2008, p. 228): "[...] a participação social contribui para a sustentabilidade, pois se um projeto é desenvolvido coletivamente, em consulta com as partes interessadas, existirá maior chance do mesmo ser sustentável”. Nessa mesma linha de pensamento, Stiglitz (2002) argumenta que, para uma transformação eficaz da sociedade rumo ao desenvolvimento, a participação é um processo necessário, pois a partir dela há o compromisso, que acarreta o esforço conjunto a fim de que os projetos tenham êxito. Para Valla (1998, p. 9), a participação social compreende "as múltiplas ações que diferentes forças sociais desenvolvem para influenciar a formulação, execução, fiscalização e avaliação das políticas públicas e/ou serviços da área social".

Apesar da falta de consenso sobre um conceito de sustentabilidade social, houve nos últimos anos, segundo Foladori (2002, p. 112): "Uma evolução no sentido de realçar a importância da participação social e também do aumento das qualidades e das potencialidades das pessoas na construção de um futuro mais justo". Para Stiglitz (2002), a partir da perspectiva da compreensão do desenvolvimento, a participação não se refere apenas ao voto; o processo participativo deve ocasionar um diálogo aberto e um amplo engajamento cívico e requer que os indivíduos tenham voz nas decisões que os afetam. Segundo Cançado, Tenório e Pereira (2011), as pessoas que são afetadas pelas decisões devem participar delas e esse processo coletivo de compartilhamento da tomada de decisão entre todos os atores participantes da ação constitui um pilar fundamental da gestão social. Em resumo, Cançado, Tenório e Pereira (2011, p. 681) destacam que a gestão social é contrária à gestão estratégica, uma vez que esta última está vinculada a mecanismos decisórios baseados na hierarquia; e os autores propõem que "a gestão social é apresentada como a tomada de decisão coletiva, sem coerção, baseada na inteligibilidade da linguagem, na dialogicidade e no entendimento esclarecido como processo, na transparência como pressuposto e na emancipação como fim último". Para Dowbor (1999), a perspectiva de uma gestão social por meio de formas participativas de discussão obriga um repensar das formas de organização social e uma redefinição da relação entre os elementos político, econômico e social, consistindo em uma dimensão humana do próprio desenvolvimento. De acordo com Almeida e Cabral (2012), a partir da definição de Tenório (1999): “A gestão social diz respeito às decisões que devem ser tomadas na igualdade política e decisória, tendo origem em processos de discussão orientados pelos princípios da inclusão, da igualdade participativa, da autonomia e do bem comum". 
Jacobi (1999, p. 38) entende a participação como:

Um processo continuado de democratização da vida municipal, cujos objetivos são: 1promover iniciativas a partir de programas e campanhas especiais visando o desenvolvimento de objetivos de interesse coletivo; 2- reforçar o tecido associativo e ampliar a capacidade técnica e administrativa de associações; e 3- desenvolver a participação na definição de programas e projetos e na gestão dos serviços municipais.

Para Cotta, Cazal e Rodrigues (2009, p. 420):

A participação da sociedade deve transcender a extensão executiva e burocrática, passando a ser pensada como um processo contínuo de democratização, o que implica o estabelecimento de uma nova sociabilidade política e um novo espaço de cidadania, onde o sujeito-cidadão deve ser o centro do processo de avaliação das ações nos serviços de saúde.

Rogers, Jalal e Boyd (2008, p. 228) utilizam a expressão desenvolvimento participativo, definindo-o "como um processo através do qual as partes interessadas influenciam ou compartilham as iniciativas de desenvolvimento, decisões, recursos, e resultados". Na ausência de vontade política e conscientização pública, é difícil de implementar o desenvolvimento participativo de um país ou de uma região. É importante mencionar que, segundo Chauí (2006), a democracia participativa é um processo de construção no qual há igualdade política e todos os cidadãos têm igual participação no poder, nas decisões e execução. Cançado, Tenório e Pereira (2011) apontam o termo "cidadania deliberativa", proposto por Tenório (2008), o qual significa que os processos de discussão pautados pelos princípios da inclusão, do pluralismo, da igualdade participativa, da autonomia e do bem comum são capazes de garantir a legitimidade das decisões. No entanto, segundo Toth, Mertens e Makiuchi (2012), no âmbito do desenvolvimento sustentável, diversos fatores limitadores dos processos de participação social têm sido verificados como relações de poder desiguais, desmotivação à participação e limites dos espaços tradicionais de participação. Justen e Moretto Neto (2012, p.11) salientam que a participação "[...] tem a função primordial da educação para uma ação responsável, individual, social e política, em que cada indivíduo apreende que os interesses público e privado encontram-se imbricados e que outros assuntos, que não os da alçada imediata dos indivíduos, devem ser considerados para fins de cooperação coletiva". Segundo Jacobi (1999, p. 35): “A noção de participação popular está associada, desde os anos 60, ao debate internacional sobre o desenvolvimento. Teve maior repercussão nos anos 70, quando do fortalecimento das propostas alternativas de desenvolvimento e da desilusão com relação à própria capacidade do Estado de controlá-lo e planificá-lo". O RDH de 2003 ressalta a importância de grupos da sociedade civil, desde organizações comunitárias a associações profissionais, passando por grupos de mulheres e redes de organizações não governamentais, os quais têm um papel fundamental nos processos participativos, mas exigem mobilização popular. Exemplos significativos têm ocorrido na formulação de políticas públicas voltadas à área da saúde, como é o caso do combate à AIDS, tuberculose e malária, como cita o referido RDH. Zaidi (2010, p. 138) salienta que:

[...] em termos de Objetivo do Desenvolvimento do Milênio 6 (controle do HIV/AIDS, malária e outras doenças), participação implica não somente um envolvimento ativo das pessoas que vivem com HIV e das comunidades afetadas no estabelecimento da agenda e na tomada de decisões, mas também a contestação de hierarquias de poder nas comunidades e sociedades em geral.

Oliveira, Cançado e Pereira (2010), referindo-se à gestão social, ressaltam que "não basta dizer que o espaço é democrático, onde todos têm direito a voz e voto, é necessário que a decisão seja coletiva, livre de coerção e que busque o entendimento, com processos baseados na transparência pública". Para os autores, se houver entendimento da gestão social enquanto possibilidade para esses espaços (mas não restrita a eles), abre-se caminho para avanços nessa conceitualização. 


\section{Experiência brasileira em participação social}

"No Brasil, a participação popular na elaboração, implementação e fiscalização das políticas públicas ganhou amplitude sem precedentes, contribuindo para aumentar tanto a eficácia e abrangência das ações públicas como a capacidade de formulação dos movimentos sociais" (MATEOS, 2011, p. 20). Segundo Avritzer (2008, p. 43),

[...] o Brasil possui hoje o que se pode denominar de uma infraestrutura da participação bastante diversificada na sua forma e no seu desenho, a qual foi sendo construída ao longo destes últimos anos a partir das experiências positivas de orçamento participativo e como resultado do processo constituinte, quando a participação popular na elaboração, acompanhamento e fiscalização das políticas públicas ganha institucionalidade.

Com a redemocratização e a promulgação da Constituição Federal de 1988 foi prevista a participação da sociedade na construção das políticas públicas (GUIMARÃES, 2007). Para Dagnino (2004, p. 97), “[...] a Constituição de 1988 é o marco formal que consagra o princípio da participação da sociedade civil nos processos de discussão e de tomada de decisão relacionados com as questões e as políticas públicas". Segundo Guimarães (2007), a sociedade conquistou o direito de, além de ser objeto das políticas públicas, tornar-se cogestores em sua elaboração e implementação. Essa participação vem transformando-se um referencial de ampliação das possibilidades de acesso dos setores populares dentro de uma perspectiva de desenvolvimento da sociedade civil e de fortalecimento dos mecanismos democráticos (JACOBI, 1999). Segundo dados do Instituto de Pesquisa Econômica Aplicada (Ipea), citados em Mateos (2011, p. 20), vários assuntos têm sido discutidos e deliberados como saneamento e habitação, políticas de geração de renda, reforma agrária, reforma urbana, direitos humanos, política cientifica e tecnológica, entre outros, além de problemas específicos como saúde indígena ou a defesa dos direitos das minorias sexuais. Para esses amplos diálogos e negociações foram criados ou ampliados diversos canais de interlocução do Estado com os movimentos sociais: conferências, conselhos, ouvidorias. Com formato congressual, algumas conferências começam com debates por bairro ou escola; todas têm etapas municipais, que discutem teses de um documento base e elegem representantes para o encontro regional ou estadual, de onde saem os delegados para a conferência temática nacional. Em todos os casos, os ministérios ou secretarias municipais e estaduais, por meio de seus delegados, também participam dos grupos de trabalho e das plenárias (MATEOS, 2011, p. 21). Até 2011 foram realizadas 73 conferências nacionais temáticas, que envolveram cerca de 5 milhões de pessoas e cujas deliberações aprovadas já se tornaram decretos, portarias ou projetos de lei aprovados ou em tramitação no Congresso Nacional, como explicita o mesmo autor. A Tabela 1 apresenta os principais conselhos nacionais de participação social.

Tabela 1

Principais conselhos de participação social

\begin{tabular}{|c|c|c|c|c|}
\hline \multicolumn{2}{|c|}{ Conselho nacional } & \multirow{2}{*}{ Criado em } & \multicolumn{2}{c|}{ Número de membros } \\
\cline { 3 - 5 } & & & Soc. civil & Governo \\
\hline 1 & Saúde & 1937 & 40 & 8 \\
\hline 2 & Defesa dos Direitos da Pessoa Humana & 1964 & 5 & 8 \\
\hline 3 & Turismo & 1966 & 37 & 32 \\
\hline 4 & Meio Ambiente & 1981 & 30 & 76 \\
\hline 5 & Direitos da Mulher & 1985 & 28 & 16 \\
\hline 6 & Curador do FGTS & 1990 & 12 & 12 \\
\hline
\end{tabular}


Continuação da Tabela 1

\begin{tabular}{|c|c|c|c|c|}
\hline \multirow{2}{*}{\multicolumn{2}{|c|}{ Conselho nacional }} & \multirow{3}{*}{$\begin{array}{c}\text { Criado em } \\
1991 \\
\end{array}$} & \multicolumn{2}{|c|}{ Número de membros } \\
\hline & & & Soc. civil & Governo \\
\hline 7 & Previdência Social & & 9 & 6 \\
\hline 8 & Direitos da Criança e do Adolescente & 1991 & 14 & 14 \\
\hline 9 & Assistência Social & 1993 & 9 & 9 \\
\hline 10 & Educação & 1995 & 10 & 14 \\
\hline 11 & Ciência e Tecnologia & 1996 & 14 & 13 \\
\hline 12 & Recursos Hídricos & 1997 & 18 & 39 \\
\hline 13 & Esporte & 1998 & 15 & 7 \\
\hline 14 & Desenvolvimento Rural Sustentável & 1999 & 19 & 19 \\
\hline 15 & Direitos da Pessoa Portadora de Deficiência & 1999 & 19 & 19 \\
\hline 16 & Direitos do Idoso & 2002 & 14 & 14 \\
\hline 17 & $\begin{array}{l}\text { Transparência Pública e Combate à } \\
\text { Corrupção }\end{array}$ & 2003 & 12 & 8 \\
\hline 18 & Desenvolvimento Econômico e Social & 2003 & 90 & 12 \\
\hline 19 & Aquicultura e Pesca & 2003 & 27 & 27 \\
\hline 20 & Economia Solidária & 2003 & 37 & 19 \\
\hline 21 & Promoção da Igualdade Racial & 2003 & 22 & 22 \\
\hline 22 & Segurança Alimentar e Nutrição & 2003 & 38 & 19 \\
\hline 23 & Cidades & 2003 & 49 & 37 \\
\hline 24 & $\begin{array}{c}\text { Comissão Nacional de Desenvolvimento dos } \\
\text { Povos e Comunidades Tradicionais }\end{array}$ & 2004 & 15 & 15 \\
\hline 25 & Combate à Discriminação & 2005 & 12 & 11 \\
\hline 26 & Juventude & 2005 & 40 & 20 \\
\hline 27 & Política Cultural & 2005 & 26 & 26 \\
\hline 28 & Políticas sobre Drogas & 2006 & 13 & 10 \\
\hline 29 & Política Indigenista & 2006 & 22 & 13 \\
\hline 30 & Brasileiro do Mercosul Social e Participativo & 2008 & 40 & 20 \\
\hline 31 & Segurança Pública & 2009 & 20 & 28 \\
\hline
\end{tabular}

Fonte: Mateos (2011, p. 22).

É importante destacar que o Programa Nacional de Habitação, o plano de expansão das Universidades Públicas, o Pro-Uni e o Programa Minha Casa Minha Vida são exemplos de políticas definidas a partir dos canais criados para a participação popular na elaboração, discussão e implementação de políticas públicas no Brasil (IPEA, 2011, p. 20). Analisando a Tabela 1, verifica-se que o primeiro conselho nacional com participação social foi o de saúde, criado em 1937, mas foi somente a partir da criação das Leis Orgânicas de Saúde (Leis n. 8.080/90 e 8.142/90) que houve a concretização da participação social nas conferências e nos 
conselhos de saúde, como instâncias deliberativas e permanentes (COTTA, CAZAL e RODRIGUES, 2009). A partir daí, os conselhos de saúde tornam-se espaços de prática da participação social no processo decisório das políticas públicas de saúde e do exercício do controle social (SALIBA et al., 2009). Essas instâncias protagonizam a participação da sociedade na gestão do sistema de saúde e articulam atores sociais portadores de interesses diferentes e olhares distintos sobre a realidade, nem sempre convergentes, onde as disputas de poder estão presentes, embora os processos de discussão busquem o consenso em defesa dos princípios e diretrizes de um sistema público resolutivo e equânime (ASSIS e VILLA, 2003 apud COTTA, CAZAL e RODRIGUES, 2009). A análise das relações de poder em um conselho de saúde possibilita um avanço na compreensão dos discursos e das práticas, informações sobre quais são os pontos de inflexão, os tipos de resistência encontrados, qual é a topografia daqueles que lá atuam.

$\mathrm{Na}$ área da cultura, Guimarães (2007) analisa que a construção do Sistema Nacional de Cultura (SNC) busca ampliar a participação social, incluindo novos atores sociais na discussão sobre as políticas de cultura, buscando, com isso, o empoderamento da sociedade, mas, ao mesmo tempo, questiona se essa participação mais ativa da sociedade consegue ser, de modo efetivo, um recurso de poder da sociedade ou se apenas, mantém-se como mais uma estrutura gerencial que se orienta pela ideia de política como troca entre governantes e governados. Outro elemento importante a ser considerado em relação à participação é a informação e o conhecimento do campo de atuação, garantindo a autonomia dos atores participantes. Cotta, Cazal e Rodrigues (2009) apontam que diferenças culturais, assim como o preparo técnico dos atores, apresenta uma influência significativa na qualidade das discussões efetuadas. Coelho (2012) ressalta algumas fragilidades democráticas, como a renovação dos membros representantes da sociedade e a possibilidade de dominação dessa representação por grupos mais organizados, como fatores limitantes para a obtenção de avanços significativos nas decisões obtidas por ocasião das discussões sobre políticas públicas na área da saúde, especificamente. Cançado, Tenório e Pereira (2012) ressaltam como problemas ao funcionamento dos conselhos gestores, o despreparo de alguns conselheiros na representação de suas instituições e o desprestigio do Estado em relação a estas instâncias. A formação dos sujeitos coletivos é condicionada pelos processos históricos, políticos, sociais, econômicos e culturais (COELHO, 2012). No Brasil, esse processo histórico caracteriza-se por períodos de colônia, império e ditadura, o que fundamenta a pouca experiência da sociedade com a democracia e a concepção de cidadania. Com base no estudo de Pinho (2010), Cançado, Tenório e Pereira (2011) salientam que, para haver a tomada de decisão coletiva sem coerção, torna-se necessária uma participação que ocorre apenas a partir da educação, o que ainda não é uma realidade no Brasil, pois: “[...] o Estado estaria aprendendo, ou tendo que aprender, a se abrir para a sociedade bem como esta teria que se instrumentalizar para forçar um diálogo efetivo com o Estado, o que representa, em ambos os casos, quebrar uma tradição historicamente constituída". Oliveira, Cançado e Pereira (2010) apontam a dificuldade de separação entre os interesses coletivos e individuais e a possibilidade de influências pessoais nas discussões dos conselhos gestores como problemas do funcionamento dessas instâncias. Para esses autores, no entanto, o fato de esses conselhos, fóruns, orçamentos participativos e todos os outros espaços públicos que vêm tomando forma no país existirem e tornarem a ação pública possível significa um avanço e a gestão social pode ser uma construção teórica que contribui para a organização e funcionamento desses espaços.

\section{Política Nacional de Controle do HIV/AIDS}

A Síndrome da Imunodeficiência Adquirida (AIDS) foi descrita pela primeira vez em 1981, sem, contudo, ser nomeada cientificamente, e em 1984 o retrovírus, considerado o agente etiológico da patologia, foi descoberto. Devido à sua rápida transmissibilidade, em 1982 a AIDS já havia sido identificada em 14 países e em 1983 em 33 países, segundo o histórico do Programa Nacional de DST/AIDS (BRASIL, 1999). A Organização Mundial da Saúde classifica a AIDS entre as doenças negligenciadas, aquelas existentes em países ricos e pobres, mas com muito maior prevalência nos últimos, fato este que justifica sua inclusão como um dos objetivos de desenvolvimento do milênio (MOREL, 2004). 
Segundo o Relatório Global sobre a Epidemia da AIDS no Mundo, em 2011, cerca de 34 milhões de pessoas viviam com a doença em todo o mundo e um total de 2,5 milhões de óbitos foi evitado em países de baixa e média renda desde 1995, devido à intensificação da terapia antirretroviral. Estima-se que 700 mil óbitos relacionados à AIDS tenham sido evitados apenas no ano de 2010. Quase a metade das pessoas (47\%) com indicação de terapia antirretroviral já estão em tratamento (UNAIDS, 2012). No entanto, apesar desses avanços, a incidência do HIV/AIDS tem aumentado em alguns países e regiões, como a África subsaariana, alguns países do Leste Europeu e da Ásia Central, o que caracteriza esse progresso obtido no combate à AIDS como frágil e desigual, segundo a Organização Mundial da Saúde (OMS, 2011). Algumas respostas nacionais ao HIV têm sido mal orientadas para a situação epidemiológica nacional e as intervenções não se dirigem adequadamente aos grupos mais vulneráveis (UNAIDS, 2011). Greco (2008) enfatiza que: “[...] na maioria dos países em desenvolvimento, a AIDS vem se somar a uma grande lista de doenças endêmicas ou emergentes como a tuberculose, hanseníase, esquistossomose, leishmaniose, malária".

No processo de exclusão social vivenciado atualmente por segmentos populacionais mais vulneráveis, as pessoas que vivem e convivem com HIV/AIDS são afetadas social e economicamente, seja na inserção no mercado de trabalho, no acesso à educação e à saúde e na participação social e comunitária (BRASIL, 2012). Após três décadas de AIDS, observa-se que o controle dessa patologia, que passou de infecção fatal a doença crônica, continua a representar um desafio para o desenvolvimento econômico e social nos diversos continentes, além de atestar a relevância da discussão integrada dos direitos humanos em políticas sociais (CARVALHO, 2008). A Política Nacional de DST/AIDS orienta as ações do Programa Nacional de DST/AIDS no âmbito da promoção à saúde, da proteção dos direitos fundamentais das pessoas com HIV/AIDS, da prevenção da transmissão das DST, do HIV/AIDS e do uso indevido de drogas; do diagnóstico, do tratamento e da assistência às pessoas que vivem com o HIV/AIDS e, ainda, orienta o desenvolvimento e fortalecimento institucional dos gestores locais dos programas e projetos na área (BRASIL, 1999). Segundo Miranda (2007), o Programa Nacional de DST/AIDS se consolidou em 1988, no mesmo ano em que foi criada a Comissão Nacional de AIDS, sendo que a sociedade contribuiu integrando comissões e grupos de trabalho específicos para auxiliar na implantação e no monitoramento das políticas públicas.

Os indicadores epidemiológicos da AIDS no Brasil ao final da década de 1980 eram muito semelhantes aos do continente africano; as análises apontavam o risco da epidemia generalizar-se na população brasileira e provocar expressivo impacto na economia e na saúde (GRANGEIRO et. al., 2006). Esse temor, que não se confirmou, justificava-se pela velocidade de crescimento da doença no Brasil, pelo surgimento de um expressivo número de novos casos entre mulheres e homens heterossexuais, pela manutenção de incidências altas em grupos sociais mais vulneráveis, além do aparecimento da doença em hemofílicos e indivíduos que haviam recebido transfusão de sangue contaminado (HASENCLEVER (2006) apud LOPES DOS SANTOS, 2010). Para Mendonça, Alves e Campos (2010), a política brasileira de HIV/AIDS foi o resultado de esforços pioneiros de um amplo espectro de diferentes grupos, desde profissionais de saúde do serviço público, da igreja católica, de associações de ativistas de direitos humanos e de grupos de risco (gays, travestis, usuários de drogas, profissionais do sexo), cuja mobilização desencadeou a inclusão da questão do HIV/AIDS na agenda política nacional. Greco (2008) afirma que a participação das pessoas com HIV/AIDS em todos os fóruns possíveis, incluindo conferências internacionais, organizações de AIDS nacionais e internacionais e agências regulatórias, na luta por seus direitos é um exemplo a ser seguido, pois esse fato fez uma grande diferença em todos os aspectos da luta pelo controle dessa epidemia. Sampaio e Araújo Jr. (2006) afirmam que os movimentos sociais, no caso da AIDS, são fortemente estruturados e possuem maciça representatividade em diversos espaços de controle e pressão social, o que tem sido evidenciado em diversos momentos como, por exemplo, sua contribuição na luta pela implantação da distribuição de medicamentos antirretrovirais. O Programa Brasileiro de DST/AIDS tem servido de exemplo para vários outros países, sendo reconhecido por organismos internacionais como o Banco Mundial e a Organização Mundial da Saúde (MENDONÇA, ALVES e CAMPOS, 2010), sendo que, dentre os seus diferenciais positivos, dois aspectos são relevantes: a distribuição gratuita de medicamentos antirretrovirais e a construção das políticas públicas específicas com ampla participação da sociedade civil (BARACAT e NOBRE, 2013; GRANGEIRO et. al., 2006). 


\section{Metodologia e Coleta de Dados}

Este estudo é caracterizado como qualitativo, considerando, segundo Creswell (2010, p. 26), que "a pesquisa qualitativa é um meio para explorar e entender o significado que os indivíduos ou os grupos atribuem a um problema social ou humano". Godoy (2006, p. 90) complementa que: "A pesquisa qualitativa abrange várias formas de pesquisa e nos ajuda a compreender e explicar o fenômeno social com o menor afastamento possível do ambiente natural". Este é um estudo exploratório, pois buscou a ampliação do conhecimento e experiência em torno dos temas pesquisados. Foi utilizada a estratégia de estudo de caso, a qual é própria para a construção de uma investigação empírica que pesquisa fenômenos dentro de seu contexto real, em profundidade, com pouco controle do pesquisador sobre eventos e manifestações do fenômeno (MARTINS, 2006; YIN, 2010).

Este trabalho utilizou evidências a partir de três tipos de fontes de dados: entrevistas semiestruturadas, observação e documentos, com a finalidade de possibilitar a triangulação dos dados, cuja função é a validação dos resultados encontrados na pesquisa (MARTINS e THEÓPHILO, 2007). Segundo Triviños (1994, p. 138): “[...] a técnica da triangulação tem por objetivo básico abranger a máxima amplitude na descrição, explicação e compreensão do foco em estudo [...]". Parte de princípios que sustentam que é impossível conceber a existência isolada de um fenômeno social, sem raízes históricas, sem significados culturais e sem vinculações estreitas e essenciais com a realidade social. A triangulação, para Yin (2010), é desenvolvida a partir do uso de múltiplas fontes de evidência capazes de desenvolver linhas convergentes de investigação. Creswell (2010) orienta que se efetue a triangulação das diferentes fontes de informação, examinando suas evidências e utilizando-as para criar uma justificativa coerente para os temas. Segundo o autor, se os temas forem estabelecidos com base nessa convergência de várias fontes de dados, pode-se dizer que esse processo está contribuindo para a validação da pesquisa.

Para a coleta dos dados desta pesquisa foram efetuadas dezenove entrevistas semiestruturadas com atores participantes do processo de formulação das políticas públicas de HIV/AIDS no Brasil, no período entre os meses de julho e outubro de 2012. Optou-se pela realização de entrevistas semiestruturadas devido à possibilidade de obtenção de informações, dados e opiniões de maneira mais espontânea e, consequentemente, de enriquecimento do processo de coleta dos dados. As entrevistas foram gravadas e posteriormente transcritas, sendo que, em caso de alguma dúvida ou necessidade de esclarecimentos posteriores, foram realizadas ligações telefônicas de curta duração aos entrevistados. $\mathrm{O}$ número de entrevistados não foi definido a priori, e a coleta foi interrompida com a saturação dos dados. Para definir essa interrupção, os dados foram tratados e analisados durante a coleta, sendo que a saturação ocorreu quando houve repetição e nenhum fato novo foi acrescentado, seguindo o proposto por Godoy (2006, p. 136): "Cabe ao pesquisador decidir quando ocorreu a saturação dos dados, ou seja, um ponto a partir do qual a aquisição de informações se torna redundante".

Os dados primários desta pesquisa foram obtidos, ainda, por meio da observação não participante, na denominação de Godoy (2006, p. 133): "[...] onde o pesquisador atua apenas como observador atento, procurando ver e registrar o máximo de ocorrências capazes de auxiliar na realização do trabalho". Os dados secundários deste estudo foram obtidos por meio da análise de diversos documentos como relatórios, boletins, notícias e documentos de Organizações Não Governamentais que atuam no controle da disseminação do HIV/AIDS.

\section{Discussão}

A participação social compreende, segundo Valla (1998, p. 9): "As múltiplas ações que diferentes forças sociais desenvolvem para influenciar a formulação, execução, fiscalização e avaliação das políticas públicas e/ou serviços básicos de saúde". Na perspectiva do Programa Nacional de DST/AIDS, essa participação ocorre formalmente a partir da Comissão Nacional de AIDS (CNAIDS), da Comissão de Articulação com os Movimentos Sociais (CAMS), dos conselhos local, estadual ou nacional de saúde, além de diversos grupos dos movimentos sociais que se organizam em inúmeras organizações não governamentais que atuam 
especificamente, ou não, no combate ao HIV/AIDS. Os gestores entrevistados esclarecem que o Departamento Nacional de DST, AIDS e hepatites virais preconiza as diretrizes e articula com os estados e os municípios a efetiva implementação das ações e projetos definidos. Portanto, a sociedade civil participa, em um primeiro nível, nas definições e formulações gerais da política de AIDS e, em um segundo nível, em sua implementação nos estados e municípios, por meio dos programas regionais e municipais de DST, AIDS e hepatites virais. Essa implementação é viabilizada por meio de um instrumento de planejamento de programação anual - Plano de Ação e Metas (PAM), o qual é definido no plano municipal ou estadual, com a participação da sociedade civil, respeitados os graus de autonomia, capacidade de execução e responsabilidades nos diversos níveis de governo. Cada Plano de Ação e Metas é, após definido e aprovado pelo Conselho de Saúde local, qualificado para recebimento de incentivo financeiro por meio de repasse de recursos do Fundo Nacional de Saúde aos fundos estaduais e municipais de saúde, conforme a Portaria Ministerial n. 2.313 (BRASIL, 2002). Há, portanto, uma descentralização dos recursos financeiros e um processo de compartilhamento de responsabilidades entre os gestores estadual, federal e municipal para viabilizar as ações e projetos definidos em cada PAM.

Esta pesquisa constatou que, na prática, muitas vezes os recursos financeiros não são alocados diretamente para os projetos definidos no Plano de Ação e Metas devido a diversos fatores, como dificuldades de relacionamento entre as secretarias de Estado e dos Municípios, interesses políticos dos gestores diferentes daqueles definidos por meio do PAM, falta de conhecimento na elaboração de projetos específicos para obtenção dos recursos, interferência de setores políticos com características conservadoras que traduzem ações discriminatórias na implementação de algumas decisões, como a questão do veto á campanha do Carnaval de 2012, orientada aos homossexuais jovens (onde a incidência de AIDS cresce), e a não distribuição do kit anti-homofobia, material composto de filmes e guia de orientação para professores que o Ministério da Educação iria distribuir em escolas públicas com o objetivo de acabar com o preconceito e a discriminação no ambiente escolar. Se o Plano de Ação e Metas, definido em conjunto com a sociedade e aprovado em uma instância na qual também há a participação social (Conselho de Saúde local), não tem sido implementado, para os atores da sociedade entrevistados, a conclusão é que essa participação não tem resolutividade, gerando uma crise no diálogo entre governo e sociedade, nesse caso específico. Para Stiglitz (2002), no contexto do desenvolvimento sustentável, o processo participativo deve ocasionar um diálogo aberto e requer que os indivíduos tenham voz nas decisões que os afetam. Sendo assim, garantir espaços de discussão nos quais as pessoas consigam manifestar suas posições e visões, de forma clara, ainda que divergentes, é imprescindível para a construção de uma democracia participativa. Formalmente, no caso em análise, das políticas públicas de AIDS, esses espaços existem por meio das diversas Comissões, Comitês, Conselhos e outros fóruns de discussão, porém, essa participação ocorre em diferentes níveis hierárquicos e varia de acordo com o nível de acesso às informações, as relações de poder e a motivação dos atores envolvidos, entre outros fatores.

No entanto, há uma fragilidade nessa estruturação, que é demonstrada pelas diferenças existentes principalmente nos níveis estadual e municipal, dependentes do gestor local e seu entendimento do processo de participação da sociedade na efetivação da política de controle do HIV/AIDS. Seguramente, são muitas variáveis e, considerando a diversidade social, política e cultural do Brasil, resultados muito distintos podem ser esperados, mas fica claro nesta pesquisa que as principais fragilidades ocorrem no processo de descentralização das ações. Assim, se as diretrizes definidas nacionalmente contemplam as demandas da sociedade civil, sua efetivação local demonstra fragilidades evidenciadas por meio do processo de descentralização dos recursos financeiros que, aliadas a características dos gestores locais e o nível de organização da sociedade civil localmente, podem comprometer sua implementação. Se, por um lado, é necessária a implantação de rígidos mecanismos de controle capazes de garantir o uso adequado e racional dos recursos financeiros do sistema público, por outro lado, a capacitação adequada para a formulação de projetos dos usuários desses recursos é tão imprescindível quanto o controle de sua liberação. Nessa perspectiva, é importante ressaltar que alguns gestores locais manifestaram sua preocupação quanto à necessidade dessa capacitação.

Esse tema remete a outra questão que consegue desequilibrar as forças na discussão envolvendo atores do Estado e da sociedade civil e que diz respeito ao acesso às informações. Somente com conhecimento 
adequado o debate poderá ocorrer em um mesmo nível, o que é essencial, pois a construção de respostas efetivas às demandas sociais somente se dará a partir do amplo debate e de olhares diversos sobre o mesmo problema. A dinâmica presente nesses espaços coletivos coloca alguns questionamentos e alguns cuidados para que a participação não se transforme em mera formalidade. A primeira questão é relativa às informações que devem ser compartilhadas entre todos. Para Chauí (2006, p. 153): "A informação é a condição mais premente da democracia, pois o indivíduo participa da vida social em proporção ao volume e à qualidade das informações que possui, mas, especialmente, em função de sua possibilidade de acesso às fontes de informação, de suas possibilidades de aproveitá-las e, sobretudo, de sua possibilidade de nelas intervir como produtor do saber". Os atores representantes da sociedade trazem suas experiências e seu conhecimento prático, mas é necessário, sem sombra de dúvida, dotá-los de conhecimentos técnicos específicos, capazes de alinhar o nível da discussão, e garantir, assim, a tomada de decisão realmente compartilhada.

Os sistemas de informação devem ser abertos à comunidade participante do processo, garantindo a existência de um diálogo aberto e consequente poder de intervenção da parcela da sociedade envolvida no processo de discussão. Assim, a existência de cursos de formação e capacitação pode auxiliar na construção de um conhecimento único e vital para o êxito de toda a discussão. Outro cuidado adicional é que a participação popular não pode, de forma alguma, representar subordinação ou redução da autonomia de organização do coletivo da sociedade. Ao contrário, é função do profissional ou dos representantes das esferas governamentais ou estatais auxiliar a desenvolver o empoderamento, por meio do conhecimento e, assim, contribuir para que o indivíduo que representa a parcela da sociedade civil no processo de elaboração e discussão coletiva deixe de ser mero espectador da realidade e passe a ser um protagonista social (COTTA, CAZAL e RODRIGUES, 2007).

Jacobi (1999, p. 35) complementa que: "Para uma efetiva participação é necessário um conjunto de prérequisitos como a melhoria de condições materiais dos grupos sociais mais excluídos através da redistribuição de recursos materiais, a redução do poder burocrático, e a institucionalização de princípios de autonomia democrática”. A participação vincula-se à capacidade de o participante tomar parte de todo o processo, isto é, de sua apropriação das etapas de diagnóstico, planejamento, implementação, acompanhamento e controle das ações.

A construção de um processo democrático de discussão coletiva não ocorre sem tensões, conflitos e disputas de poder. Faria (2009) considera o Estado a forma organizada da sociedade, compreendendo, assim, o Estado como uma organização com sua gestão formal regida por um conjunto de normas. Assim, os representantes do Estado nesses processos de formulação conjunta devem ser capazes de contribuir para que os representantes da sociedade civil sejam capazes de se apropriar das informações relativas ao tema em discussão. Caso contrário, a reprodução de mecanismos de dominação que existem dentro de uma organização, como descrito por Morgan (1996), com a divisão da organização em dois mundos, caracterizados por comportamentos políticos, irão refletir e reforçar as divisões de classe encontradas na sociedade. Entende-se que deve haver uma ação conjunta de aprendizagem social, visando à construção de novos tipos de relações sociais, sendo que do lado da sociedade civil alguns elementos podem dificultar uma participação igualitária nos espaços públicos, tornando-se necessária uma qualificação técnica e política de representantes de ambas as partes (DAGNINO, 2004). Sampaio e Araújo Jr. (2006) também apontam a existência de conflitos sociais nas discussões de políticas públicas e, segundo os autores, é esse conflito que mantém a dinâmica social. Os atores que participam desses processos de discussão são portadores de interesses e olhares distintos sobre a realidade, nem sempre convergentes, e as disputas de poder estão presentes (ASSIS e VILLA, 2003 apud COTTA, CAZAL e RODRIGUES, 2009).

Deve-se ressaltar que a participação é uma conquista da sociedade e deve ser assegurado o direito de cada um se expressar, ser ouvido e considerado e exercer oposição quando necessário. Stotz (2008) apud Pereira (2010) salienta que onde a participação popular não tem tradição de luta e organização, esta pode ser apenas uma forma de legitimar os atos dos gestores. A garantia dessa participação se dá por meio da estruturação e representatividade dos movimentos sociais e, principalmente, de sua autonomia em relação ao Estado, ainda que sua sobrevivência enquanto organização ocorra na dependência dos recursos financeiros estatais. Zaidi (2010, p. 138), analisando a questão dos direitos humanos em relação às políticas de controle do HIV/AIDS, 
afirma que a participação, no caso do HIV/AIDS, significa a contestação de hierarquias de poder nas comunidades e sociedades em geral. A implementação dessa participação tem ocorrido devido à capacidade de mobilização, articulação e organização da sociedade por meio de seus movimentos, como a Rede Nacional de Pessoas que vivem com o HIV/AIDS ou por meio de ONGs. Essas organizações garantem a realização do debate, possibilitam o avanço que se dá a partir de olhares distintos e legitimam as políticas públicas, contribuindo para que atendam às reais necessidades da sociedade e do público a que são destinadas. A essência da discussão em torno da participação se refere ao processo de construção da tomada de decisão coletiva e à criação de alicerces de uma gestão social para a construção de uma sociedade baseada na democracia participativa.

\section{Considerações Finais}

Este estudo teve por objetivo caracterizar a participação social como medida de análise qualitativa da sustentabilidade social e, para tanto, efetuou-se um estudo de caso que buscou avaliar a participação da sociedade na construção das políticas públicas de controle do HIV/AIDS no Brasil. Inicialmente, foi apresentado um contexto global evidenciando a questão do crescimento demográfico, da desigualdade social e o fato de que, apesar de todo o avanço tecnológico e produção de riqueza material, as desigualdades socioeconômicas têm permanecido ou até aumentado em alguns locais, as quais contribuem para que problemas de saúde como algumas doenças infecciosas, entre elas a AIDS, que poderiam ser evitadas, persistam e ainda causem sérias ameaças ao próprio desenvolvimento econômico e social. O referencial teórico procurou evidenciar que a conquista do desenvolvimento sustentável sob a perspectiva social visa à melhoria da qualidade de vida da população como um todo, na perspectiva do atendimento das necessidades das gerações do presente e do futuro. Nesse sentido, configura-se um novo paradigma que envolve justiça social, qualidade de vida, equilíbrio ambiental e desenvolvimento econômico, representando uma transformação nas relações tradicionais da sociedade, o que envolve a ampliação e a democratização das relações de poder, sendo que as práticas de participação nas discussões sobre políticas públicas são essenciais para que obtenham representatividade e comprometimento dos setores envolvidos em sua formulação, compreendendo-se, dessa forma, que a participação social pode ser um dos elementos de análise da sustentabilidade social. Esta pesquisa contribuiu, ainda, para aprofundar o campo de estudos empíricos sobre gestão social. No caso prático estudado neste artigo, sobre políticas de controle do HIV/AIDS, verificou-se que, formalmente, por meio das diversas comissões e discussões regionais do Plano de Ação e Metas, a participação de setores da sociedade existe, no entanto, a heterogeneidade cultural, econômica, social e política do país faz com que as ações implementadas e, consequentemente, seus resultados sejam distintos, apesar das políticas públicas nessa área serem definidas nacionalmente. Nesse sentido, por meio dos achados desta pesquisa, pode-se afirmar que a participação ocorre formalmente, mas não tem sido capaz de romper as hierarquias tradicionais de poder existentes em nossa sociedade. Essa afirmação se baseia no fato de que, embora as diretrizes sejam definidas nacionalmente e contemplem as demandas da sociedade, sua implementação se dá em nível estadual e municipal. Assim, pode-se afirmar que essa participação tem ocorrido muito mais como um recurso gerencial, capaz apenas de reforçar os atos dos gestores, do que como um recurso de poder da sociedade, facilitando respostas para as demandas comunitárias. É importante salientar que a participação da sociedade não deve servir apenas para legitimar os atos dos gestores, pois o avanço na formulação das políticas públicas ocorre a partir da discussão efetuada entre todos os segmentos da sociedade. Ou seja, as políticas não serão efetivas se não houver a participação do cidadão, trazendo sua demanda e contribuição por meio de seu conhecimento e de sua experiência.

Portanto, o estudo contribuiu para estimular novas pesquisas para o aperfeiçoamento e a discussão das dificuldades regionais mencionadas na implantação das políticas públicas de HIV/AIDS, da participação da sociedade na formulação de políticas públicas e da perspectiva dessas políticas sob a ótica do desenvolvimento sustentável.

Buscando aprofundar o conhecimento sobre o tema investigado, este artigo sugere quatro campos de pesquisas futuras: (i) Construção do capital social relacionado às políticas de HIV/AIDS, onde se deve trabalhar na perspectiva de garantir espaços de discussão para que as pessoas consigam manifestar suas 
posições, ainda que divergentes, e capacitar o usuário nos mecanismos de utilização de recursos públicos; (ii) Investigação da relação entre nível de alfabetismo ou escolaridade, nível de participação social e desempenho das políticas de controle do HIV/AIDS nas diferentes regiões do território brasileiro; (iii) Proposição da gestão social como processo de ampliação da participação e de libertação do poder popular, o qual tem sido restringido por instrumentos de gestão estratégica baseada na hierarquia. Nesse campo, deve-se avançar na perspectiva do controle social, onde a participação não seja apenas um elemento gerencial, mas se transforme em um recurso de poder, capaz de influenciar por meio de decisão coletiva, no acompanhamento e na avaliação das políticas, pois é nesse contexto da participação social que se constrói a sustentabilidade social; (iv) Aprofundamento da compreensão das relações de poder existentes entre os atores que participam das discussões de formulação das políticas de AIDS no Brasil.

Este estudo apresentou algumas limitações, especialmente derivadas do método de pesquisa utilizado, no que se refere à impossibilidade de generalização dos resultados e à possibilidade de influência do pesquisador na interpretação do fenômeno e dos resultados.

\section{Referências}

ALMEIDA, E. A. C.; CABRAL, E. H. S. Os valores e os instrumentos de gestão social: um estudo de casos múltiplos com conselhos de direitos da criança e do adolescente. In: ENCONTRO NACIONAL DE PESQUISADORES EM GESTÃO SOCIAL, 6., 2012, São Paulo. Anais... São Paulo: [s. n.], 2012.

ALMEIDA, F. Os desafios da sustentabilidade: uma ruptura urgente. Rio de Janeiro: Elsevier, 2007.

ASSIS, M.M.A.; VILLA T.C.S. O controle social e a democratização da informação: um processo em construção. Revista Latino-Americana de Enfermagem, Ribeirão Preto, v. 11, n. 3, p. 376-82, 2003.

AVRITZER, L. Instituições participativas e desenho institucional: algumas considerações sobre a variação da participação no Brasil democrático. Opinião, v. 14, n. 2, p. 43-64, 2008.

BARACAT, M. M. Z.; NOBRE, F. S. Innovating and serving the poor with antiretroviral drug systems: advances in the HIV Brazilian Program. In: MUGA, Helen E.; THOMAS, Ken D. (Org.). Cases on the diffusion and adoption of sustainable development practices. New York: IGI Global, 2013. p. 1-19.

BARBIERI, J. C. et al. Inovação e sustentabilidade: novos modelos e proposições. Revista de Administração de Empresas, São Paulo, v. 50, n. 2, p. 146-154, jun. 2010.

BARBOSA, G. S. O desafio do desenvolvimento sustentável. Revista Visões, v. 4, n. 1, p.1-11, jan./jun. 2008.

BEZERRA, M. C. L.; BURSZTYN, M. (cood.). Ciência e Tecnologia para o desenvolvimento sustentável. Brasília: Ministério do Meio Ambiente e dos Recursos Naturais Renováveis: Consórcio CDS/ UNB/ Abipti, 2000.

BLOOM, E. E.; CANNING, D. Booms, busts, and echoes. How the biggest demographic upheaval in history is affecting global development. Finance \& Development, p. 8-13, Sep. 2006. Disponível em: <http://www.imf.org/external/pubs/ft/fandd/2006/09/bloom.htm>. Acesso em: 14 mar. 2012.

BOYLE, M. E.; BOGUSLAW, J. Business, poverty and corporate citizenship: naming the issues and framing solutions. Journal of Corporate Citizenship, p. 101-122, 2007. Disponível em: <http://www.sba.pdx.edu/faculty/scottm/smaccess/GlobalSustainability/Day\%202\%20Readings/Business, \%20Poverty \%20and\%20Corporate\%20Citizenship\%20-20Boyle\%20and\%20Buguslaw\%20JCC.pdf->. Acesso em: 7 set. 2012.

BRASIL. Política Nacional de DST/AIDS: princípios, diretrizes e estratégias. Brasília, DF: Ministério da Saúde, 1999. Disponível em: <http://www.ilo.org/wcmsp5/groups/public/---ed_protect/--protrav/--ilo_aids/documents/legaldocument/wcms_127698.pdf>. Acesso em: 12 abr. 2012. 
$\begin{array}{ccccccc}\text { Portaria } & \text { n. }{ }^{\circ} & \text { 2313/GM } & \text { Em } & 19 & \text { de dezembro de } \\ \text { http://www.brasilsus.com.br/legislacoes/gm/7354-2313.html. Acesso em } 07 \text { mar. } 2013 .\end{array}$

Adesão ao tratamento antirretroviral no Brasil: coletânea de estudos do Projeto ATAR. Brasília, DF: Ministério da Saúde, 2010.

CALLINICOS, A. Igualdade e capitalismo. In: BORO, A.; AMADEO, J.; GONZALEZ, S. (Org.). A teoria marxista hoje: problemas e perspectivas. São Paulo: Expressão Popular, 2006. p. 253-269.

CANÇADO, A. C.; TENÓRIO, F. G.; PEREIRA, J. R. Gestão social: reflexões teóricas e conceituais. Cad. EBAPE.BR, v. 9, n. 3, p. 681-703, set. 2011.

CARVALHO, G. S. Pessoas vivendo com HIV/AIDS: vivências do tratamento antirretroviral. 2008.99 f. Dissertação (Mestrado em Saúde Coletiva) - Programa de Pós-Graduação em Saúde Coletiva, Universidade Estadual de Londrina, Londrina, 2008.

CHAUÍ, M. Cultura e democracia: o discurso competente e outras falas. 11. ed. São Paulo: Cortez, 2006.

COELHO, J. S. Construindo a participação social no SUS: um constante repensar em busca da equidade e transformação. Saúde e Sociedade, v. 21, p. 138-151, 2012. Suplemento.

COMISSÃO ECONÔMICA PARA A AMÉRICA LATINA E O CARIBE - CEPAL. Globalização e desenvolvimento. 2002. Disponível em: <http://www.eclac.org/publicaciones/xml/9/10029/ApresentacaoGlobalizacion.pdf>. Acesso em: 23 mar. 2012.

Perspectivas económicas de América Latina 2012: Transformación del Estado para el Desarrollo. 2011. Disponível em: <http://dx.doi.org/10.1787/leo-2012-es〉. Acesso em: 19 nov. 2012.

COMISSÃO MUNDIAL SOBRE MEIO AMBIENTE E DESENVOLVIMENTO - CMMAD. Nosso futuro comum. Rio de Janeiro: Ed. FGV, 1991.

COTTA, R. M. M.; CAZAL, M. M.; RODRIGUES, J. F. C. Participação, controle social e exercício da cidadania: a (des)informação como obstáculo à atuação dos conselheiros de saúde. Physis, v. 19, n. 2, p. 419-438, 2009. Disponível em: <http://www.scielo.br/scielo.php?script=sci_arttext\&pid=S0103-73312009000200010\&lng=en\&nrm=iso>. Acesso em: 29 set. 2012.

CRESWELL, L. W. Projeto de pesquisa: métodos, qualitativo, quantitativo e misto. 2. ed. Porto Alegre: Artmed, 2010.

DAGNINO, E. Sociedade civil, participação e cidadania: de que estamos falando? In: MATO, D. (Org.). Políticas de cidadania y sociedade civil em tiempos de globalización. Caracas: Faces, 2004.

DILLARD, J. F.; DUJON, V. Understanding the social dimension of sustainability. 2009. Disponível em: <http://books.google.com.br/books/about/Understanding_the_Social_Dimension_of_Su.html?id=HhaAWT47pEC\&redir_esc=y>. Acesso em: 28 abr. 2012.

DONELLA, H. M. et al. The limits to growth: a report for the Club of Rome's project on the predicament of mankind. New York: Universe Books, 1972.

DOWBOR, L. Tendencias da gestão social. Saúde e sociedade, v. 8, n. 1, p. 3-16, 1999. Disponível em: <http://www.scielo.br/scielo.php?script=sci_arttext\&pid=S0104-12901999000100002\&lng=en\&nrm=iso>. Acesso em: 17 mar. 2013.

ELKINGTON, J. Towards the sustainable corporation: win-win-win business strategies for sustainable development. California Management Review, v. 36, n. 2, p. 90-100, 1994.

Cannibals with forks: the tripple bottom line of $21^{\text {st }}$ Century business. Oxford: Capstone, 1997. 
FARIA, J. H. Gestão participativa: relações de poder e de trabalho nas organizações. São Paulo: Atlas, 2009.

FOLADORI, G. Avanços e limites da sustentabilidade social. Revista Paranaense de Desenvolvimento, n. 102, p.

103-113, 2002. Disponível em:
<http://www.ipardes.pr.gov.br/ojs/index.php/revistaparanaense/article/viewFile/214/176>. Acesso em: 28 abr. 2012.

; TOMMASINO, H. El enfoque técnico y el enfoque social de la sustentabilidad. Revista Paranaense de
Desenvolvimento
n. 98 ,
p.
67-75,
2000.
Disponível
em:

<http://www.ipardes.pr.gov.br/ojs/index.php/revistaparanaense/article/view/253>. Acesso em: 7 set. 2012.

FUNDAÇÃO OSWALDO CRUZ - FIOCRUZ. As causas sociais das iniquidades em saúde no Brasil. Rio de Janeiro: Ed. Fiocruz, 2008.

GLADWIN, T. N.; KENNELLY, J. J.; KRAUSE, T. Shifting paradigms for sustainable development: implications for management theory and research. Academy of Management Review, v. 20, n. 4, p. 874-907, Oct. 1995.

GODOY, C. K. et al. Pesquisa qualitativa em estudos organizacionais: paradigmas, estratégias e métodos. São Paulo: Saraiva, 2006.

GRANGEIRO, A. et al. Sustentabilidade da política de acesso a medicamentos antirretrovirais no Brasil. Revista de Saúde Pública, v. 40, p. 60-69, 2006. Suplemento.

GRECO, D. B. A epidemia da AIDS: impacto social, científico, econômico e perspectivas. Estudos Avançados, v. 22 , n. 64, p. 73-94, 2008.

GUIMARÃES, R. G. A participação da sociedade na construção das políticas públicas culturais no Brasil: um recurso gerencial ou de poder? In: CONFERENCIA REGIONAL DE ISTR PARA AMÉRICA LATINA E CARIBE, 6., 2007, Salvador. Anais... Salvador: [s. n.], 2007. Disponível em: <http://www.google.com.br/\#hl>. Acesso em: 28 nov. 2012.

HARRIS, J. M.; GOODWIN, N.R. "Volume Introduction". In A Survey of Sustainable Development: Social and Economic Dimesions, edited by Jonathan M. Harris, Timothy A. Wise, Kevin P. Gallagher and Neva R. Goodwin. Washington, DC: Island Press, 2001.

HART, S. L. O capitalismo na encruzilhada: as inúmeras oportunidades de negócios na solução dos problemas mais difíceis do mundo. Porto Alegre: Bookman, 2006.

; MILSTEIN, M. B. Criando valor sustentável. RAE executivo, v. 3, n. 2, p. 65-79, 2004.

HASENCLEVER, L. (Coord.). Propriedade intelectual, política industrial-tecnológica e mercado de antiretrovirais. Rio de Janeiro: IE/UFRJ - ANRS, 2006.

HAWKEN, P.; LOVINS, A; LOVINS, L. H. Natural capitalism. Boston: Little, Brown \& Company, 1999.

HINKELAMMERT, F. A globalidade da terra e a estratégia da globalização. In: BORO, A.; AMADEO, J.; GONZALEZ, S. (Org.). A teoria marxista hoje: problemas e perspectivas. São Paulo: Expressão Popular, 2006.p. 351364.

HOBSBAWM, E. Era dos extremos: o breve século XX - 1914-1991. 2. ed. São Paulo: Companhia das Letras, 2010.

IANNI, O. A sociedade global. 8. ed. Rio de Janeiro: Civilização Brasileira, 1999.

IPIRANGA, A. S. R.; GODOY, A. S.; BRUNSTEIN, J. Editorial. Revista de Administração Mackenzie, v. 12, n. 3, 2011. Edição especial.

JACOBI, P. Poder local, políticas sociais e sustentabilidade. Saúde e Sociedade, v. 8, n. 1, p. 31-48, 1999. Disponível em: 〈http://www.scielo.br/pdf/sausoc/v8n1/04.pdf>. Acesso em: 28 out. 2012. 
JUSTEN, C.; MORETTO NETO, L. Que participação é essa? Do instrumentalismo legitimador à autopromoção emancipadora. In: ENCONTRO NACIONAL DE PESQUISADORES EM GESTÃO SOCIAL, 6, 2012 , São Paulo. Anais... São Paulo: [s. n.], 2012.

KANDACHAR, P.; HALME, M. Sustainability challenges and solutions at the base of the pyramid: business, technology and the poor. Sheffield: Greenleaf, 2008.

LITTIG, B.; GRIEBLER, E. Social sustainability: a catchword between political pragmatism and social theory. International Journal of Sustainable Development, v. 8, n. 1/2, p. 65-79, 2005.

LOPES DOS SANTOS, R. S. Sustentabilidade do Programa Nacional de DST/AIDS: análise da capacidade de oferta e preços dos medicamentos antirretrovirais. 2010. 227 f. Dissertação (Mestrado em Políticas Públicas, Estratégia e Desenvolvimento) - Instituto de Economia, Universidade Federal do Rio de Janeiro, 2010.

LUSTIG, N.; LÓPEZ-CALVA, L. F. El mercado laboral, el Estado y la dinámica de la desigualdade em América Latina: Brasil, México U $\quad 2012 . \quad$ Disponível em: <http://www.pensamientoiberoamericano.org/xnumeros/10/pdf/pensamientoIberoamericano-194.pdf >. Acesso em: 20 nov. 2012

MARTINS, G. A. Estudo de caso: uma estratégia de pesquisa. São Paulo: Atlas, 2006.

MARTINS, G. A.; THEÓPHILO, C. R. Metodologia da investigação científica para ciências sociais aplicadas. São Paulo: Atlas, 2007.

MATEOS, S. B. A construção da democracia participativa. Revista Desafios do Desenvolvimento, v. 65, n. 8, p. 1833,2011

MENDONÇA, P. M. E.; ALVES, M. A.; CAMPOS, L. C. Empreendedorismo institucional na emergência do campo de políticas públicas em HIV/AIDS no Brasil. RAE Eletrônica, v. 9, n. 1, 2010.2 Disponível em: <http://www.scielo.br/scielo.php?script=sci_arttext\&pid=S167656482010000100007\&lng=en\&nrm=iso>. Acesso em: 25 abr. 2012.

MIRANDA, A. A. Movimentos sociais, Aids e cidadania: a construção social do direito à saúde no Brasil. 2007.149 f. Dissertação (Mestrado em Direito) - Universidade de Brasília, Brasília, 2007.

MONTEIRO, A. L. O. Relação Estado e sociedade civil no processo de formulação e implementação de políticas públicas. Análise do Programa Nacional de DST/AIDS (1980-2006). 2006. 141 f. Dissertação (Mestrado em Gestão Social e Trabalho) - Faculdade de Economia, Administração, Contabilidade e Ciência da Informação e Documentação, Brasília, 2006.

MOREL, C. M. A pesquisa em saúde e os objetivos do milênio: desafios e oportunidades globais, soluções e políticas nacionais. Ciência \& Saúde Coletiva, v. 9, n. 2, p. 261-270, 2004

MORGAN, G. Imagens da organização. São Paulo: Atlas, 1996.

NIDUMOLU, R.; PRAHALAD, C. K.; RANGASWAMI, M. R. Why sustainability is now the key driver of innovation? Harvard Business Review, v. 87, n. 9, p. 56-65, Sep. 2009. Disponível em: <https://www.acteonline.org/uploadedFiles/Why\%20Sustainability\%20Is\%20Now\%20the\%20Key\%20Driver\%20of\% 20Innovation\%20Harvard\%20Review.pdf>. Acesso em: 29 abr. 2012.

NOBRE, F. S.; WALKER, D.; HARRIS, R. Technological, managerial and organizational core competencies: dynamic innovation and sustainable advantage. New York: Information Science Reference/IGI Global, 2011.

OLIVEIRA, G. B. Uma discussão sobre o conceito de desenvolvimento. Revista FAE, v. 2, n. 5, p. 37-48, 2002.

OLIVEIRA, V. A. R.; CANÇADO, A. C.; PEREIRA, J. R. Gestão social e esfera pública: aproximações teóricoconceituais. Cad. EBAPE.BR, v. 8, n. 4, p. 613-626, dez. 2010. 
OMANN, I.; SPANGENBERG, J. H. Assessing social sustainability. In: BIENNIAL CONFERENCE OF THE INTERNATIONAL SOCIETY FOR ECOLOGICAL ECONOMICS, 7, 2002, Sousse, Tunisia. Annals. Sousse: [s. n.], 2002.

Organização Mundial da Saúde - OMS, Estratégias AIDS 2011- 2015, 2011. Disponível em: < http://www.who.int/topics/hiv_aids/en/. Acessado em 4 nov. 2012.

Organização para a Educação, a Ciência e a Cultura das Nações Unidas- UNESCO. Década da Educação das Nações Unidas para um Desenvolvimento Sustentável, 2005-2014: documento final do esquema internacional de implementação: Brasília, DF, 2005.

PEREIRA, A. J. A sociedade civil organizada no enfrentamento da Aids no município de São Paulo. 2010.119 f. Dissertação (Mestrado em Ciências) - Escola de Enfermagem, Universidade de São Paulo, São Paulo, 2010.

PINHO, J.A.G. In: RIGO, A. et al. Gestão social e políticas públicas de desenvolvimento: ações, articulações e agenda. (org). Recife: UNIVASF, 2010. 456 p.

PORTER, M. E.; KRAMER, M. R. Creating shared value: how to reinvest capitalism and unleash a wave of innovation and growth. Harvard Business Review, v. 89, n. 1/2, p. 1-17, Jan./Feb. 2011.

PRAHALAD, C. K. A riqueza na base da pirâmide: erradicando a pobreza com o lucro. Porto Alegre: Bookman, 2010 .

PRETTY, J. N. Participatory learning for sustainable agriculture. World Development, v. 23, n. 8, p. 1247-1263, 1995. Disponível em: 〈http://www.sciencedirect.com/science/article/pii/0305750X9500046F>. Acesso em: 23 out. 2012.

PROGRAMA DAS NAÇÕES UNIDAS PARA O DESENVOLVIMENTO - PNUD. Relatório do Desenvolvimento Humano. 1993. Disponível em: <http://hdr.undp.org/en/reports/global/hdr1993/>. Acesso em: 27 out. 2012.

_. Relatório do Desenvolvimento Humano. 2011. Disponível em: <http://hdr.undp.org/en/reports/global/hdr2011/download/pt/>. Acesso em: 15 set. 2012.

RODRIGUES, M. C. P. O índice do desenvolvimento humano (IDH) da ONU. Revista Conjuntura Econômica, Rio de Janeiro, julho 1993.

ROGERS, P. P.; JALAL, K. F.; BOYD, J. A. An introduction to sustainable development. London: Earthscam, 2008.

SACHS, I. Espaços, tempos e estratégias de desenvolvimento. São Paulo: Vértice, 1986.

Estratégias de transição para o século XXI: desenvolvimento e meio ambiente. São Paulo: Nobel, 1993.

Desenvolvimento numa economia mundial liberalizada e globalizante: um desafio possível? Estudos Avançados, v. 11, n. 30, p. 213-242, 1997.

SALIBA, N. A. et al. Conselhos de saúde: conhecimento sobre as ações de saúde. RAP, v. 43, n. 6, p. 1369-1378, nov./dez. 2009. Disponível em: <http://www.scielo.br/pdf/rap/v43n6/07.pdf>. Acesso em: 29 set. 2012.

SAMPAIO, J.; ARAÚJO JR., J. L. Análise das políticas públicas: uma proposta metodológica para o estudo no campo da prevenção em Aids. Revista Brasileira de Saúde Materno Infantil, v. 6, n. 3, Sep. 2006. Disponível em: <http://www.scielo.br/scielo.php?script=sci_arttext\&pid=S151938292006000300010\&lng=en\&nrm=iso>. Acesso em: 25 abr. 2012.

SEN, A. Globalmente resignados. Revista de Economía Institucional, v. 4, n. 6, p. 222-226, 2002. Disponível em: <http://econpapers.repec.org/article/reiecoins/v_3a4_3ay_3a2002_3ai_3a6_3ap_3a222-226.htm>. Acesso em: 22 out. 2012.

Desenvolvimento como liberdade. São Paulo: Companhia das Letras, 2009. 
STIGLITZ, J. E. Participation and development: perspectives from the comprehensive development paradigm. Review of Development Economics, v. 6, n. 2, p. 163-182, 2002 . Disponível em: <http://siteresources.worldbank.org/INTEMPOWERMENT/Resources/14549_5869557_1_061803.pdf〉. Acesso em: 22 out. 2012.

STOTZ, E. N. Movimentos sociais e saúde: notas para uma discussão. Cadernos de Saúde Pública 1994 v. 10, n. 2 , p. 264-268.

TENÓRIO, F.G. Inovando com democracia, ainda uma utopia. Revista de Administração Pública, Rio de Janeiro, FGV, v. 33, p. 229-238, 1999.

Tem razão a administração? $3^{\text {a }}$ ed. Ijuí: Editora da Unijuí, 2008.

TOTH, M.; MERTENS, F.; MAKIUCHI, M. F. R. Novos espaços de participação social no contexto do desenvolvimento sustentável: as contribuições da educomunicação. Ambiente \& Sociedade, v. 15, n. 2, p. 113-132, maio/ago. 2012.

TRIVIÑOS, A. N. S. Introdução à pesquisa em ciências sociais: a pesquisa qualitativa em educação. São Paulo: Atlas, 1994.

UNITED NATIONS PROGRAMME ON HIV/AIDS - UNAIDS. Estratégia UNAIDS/ONUAIDS 2011-2015. Disponível em: <http://www.unaids.org/en/media/unaids/contentassets/documents/unaidspublication/2010/JC2034_UNAIDS_Strategy_ pt.pdf.>. Acesso em: 27 nov. 2012

Relatórios Epidemia AIDS 2012. Disponível em: http://www.unaids.org.br/arquivos/FS-Global.pdf, acesso em: 04 abr. 2012.

UNITED NATIONS WORLD COMMISSION ON ENVIRONMENT AND DEVELOPMENT - WCED. Our common future. Oxford: Oxford University Press, 1987.

VALlA, V. V. Sobre participação popular: uma questão de perspectiva. Cadernos de Saúde Pública, v. 14, p. 7-18, 1998. Disponível em: <http://www.scielosp.org/pdf/csp/v14s2/1322.pdf〉. Acesso em: 22 nov. 2012.

VEIGA, J. E. Meio ambiente e desenvolvimento. 2. ed. São Paulo: Senac, 2008.

VELLANI, C. L.; RIBEIRO, M. S. Sustentabilidade e contabilidade. Revista Contemporânea de Contabilidade, v. 11, n. 1, p. 187-206, 2009.

VIVIEN, F. D. Economia e ecologia. São Paulo: Senac, 2011.

YIN, R. K. Estudo de caso: planejamento e métodos. 4. ed. Porto Alegre: Bookman, 2010.

ZAIDI, S. Objetivo 6 do desenvolvimento do milênio e o direito à saúde: contraditórios ou complementares? SUR, v. 7 , n. 12, p. 129-151, jun. 2010. Disponível em: 〈http://www.surjournal.org/conteudos/pdf/12/07.pdf〉. Acesso em: 28 nov. 2011. 